\title{
Paulo Freire e a questão nacional
}

\author{
Ricardo Prestes Pazello ${ }^{1}$
}

\section{Resumo}

Este texto tem por objetivo refletir sobre a produção teórica de Paulo Freire, tomando a questão nacional como seu fio condutor e as consequências de sua interpretação para suas opções epistemológicas. A análise ressalta dois momentos de sua produção, os quais carregam consigo entendimentos distintos referentes à problemática nacional, em um primeiro instante, marcada pelo desenvolvimentismo e, em um segundo, pela crítica à dependência política e econômica.

\section{Palavras-chave}

Paulo Freire. Questão Nacional. História da Educação Popular.

1. Doutorando em Direito das Relações Sociais pela Universidade Federal do Paraná, professor de Antropologia Jurídica e pesquisador do Núcleo de Estudos Filosóficos (NEFIL) na mesma instituição; membro do grupo de pesquisa "Direito, Sociedade e Cultura" (FDV/ES); integrante do Instituto de Pesquisa, Direitos e Movimentos Sociais (IPDMS), do Centro de Formação Milton Santos-Lorenzo Milani (Santos-Milani) e do Instituto de Filosofia da Libertação (IFiL); colunista do blog < assessoriajuridicapopular.blogspot.com>. E-mail: ricardo2p@ufpr.br. 


\title{
Paulo Freire and the national question
}

Ricardo Prestes Pazello*

\begin{abstract}
This text aims to get a reflection about the Paulo Freire's theoretical production, considering the national question as guidance and the interpretation consequences to their epistemological options. The analysis emphasizes two moments of its production, which brings different understandings referred to the national problematic, at first, remarkable by developmentalism, and second, by political and economic dependence criticism.
\end{abstract}

\section{Keywords}

Paulo Freire. National Question. Popular Education History.

* Candidate for a doctor's degree in Social Relations Law at the Federal University of Paraná, Juridical Anthropology professor and Philosophical Studies researcher at Núcleo de Estudos Filosóficos (NEFIL); group research member "Direito, Sociedade e Cultura" (FDV/ES); Instituto de Pesquisa, Direitos e Movimentos Sociais (IPDMS) component from Centro de Formação Milton Santos-Lorenzo Milani (Santos-Milani) and Instituto de Filosofia da Libertação (IFiL); <assessoriajuridicapopular.blogspot.com> blog columnist. E-mail: ricardo2p@ufpr.br. 


\section{Introdução}

Apodrecerei no cárcere com esta idéia. Morrerei com ela. É uma obsessão, sim, uma obsessão não de um general, mas de um humilde soldado da Gloriosa Revolução Latino-Americana. É uma paixão, meu amor, a violenta paixão de um patriota ${ }^{2}$.

Francisco Julião

Foram estas as palavras de Francisco Julião, eminente militante das Ligas Camponesas no Brasil, as quais tinham por objetivo maior a libertação dos campônios brasileiros e a construção de uma pátria livre. Certamente, não foi somente sua prisão que o levou a dizê-las.

Paulo Freire, a quem estas notas pretendem se referir, também teve seus momentos no cárcere e, como Julião, não foram eles os determinantes de uma práxis de resistência. A pedagogia do oprimido germinaria ali, na exterioridade negada dos grilhões que não possuem rosas a thes cobrir a ferrugem.

Antes, contudo, de nos demorarmos na investigação do nacional em Paulo Freire, é preciso fazer notar que sua obra não descura, em sua mirada geral, da compreensão da necessidade da integração latino-americana, daí porque as linhas de Francisco Julião vêm a calhar.

Temos por ponto de partida - que, cremos, precisa ser explicitado - o contexto de produção teórica que uniu, à década de 1970, grandes nomes das humanidades latinoamericanas. Assim, não só Paulo Freire desponta com Pedagogia do Oprimido (2004), livro que refunda seu caminho teórico, fruto que foi da violência do exílio, mas também nomes como o de Enrique Dussel, cuja obra síntese será Filosofia da Libertação ([198-]), Alfredo Moffatt e sua Psicoterapia do Oprimido (1983), e, ainda, a Teologia da Libertação, de Gustavo Gutiérrez (1984) e o Teatro do Oprimido, de Augusto Boal (1991) apareceriam na explosão continental de denúncia e contestação da situação vil pela qual passava o continente.

Esta observação torna-se necessária, tendo em vista a premência de se conceber a obra freireana não desligada de um todo maior da qual fazia parte e que encontrava nele respaldo mútuo para um questionamento das estruturas opressoras que sufocavam (e ainda sufocam) a América Latina, pois

ainda para a compreensão radical de cada uma de nossas culturas nacionais deveremos contar com as estruturas da cultura latinoamericana. (DUSSEL, 1997, p. 43-44).

Assim, procuraremos estabelecer um guia de leitura para compreender a questão nacional na obra de Paulo Freire. Não se trata de uma mirada acerca do conceito de "nacional" em seu pensamento, mas antes os traços que, em épocas distintas de sua produção, se apresentam marcantes para o seu esforço teórico e prático em busca da libertação.

Nesse sentido, o problema nacional é mais um elemento não causal que uma chave analítica, ou seja, as mudanças nas perspectivas de Freire levaram a transformar seu entendimento do nacional e de seu lugar em suas reflexões. É um fio condutor apenas neste aspecto. Portanto, trata-se de item periférico em seu discurso, mas que, ao mesmo tempo, permite compreender o contexto a partir do qual se engajava, seja em um ambiente nacionaldesenvolvimentista, seja a partir da crítica à dependência latino-americana ou, ainda, no seio da tentativa da construção do socialismo em África. Vale dizer: três possibilidades consequenciais para o enfrentamento da questão nacional em Paulo Freire.

Como é perceptível, pretendemos muito mais um pequeno escorço histórico da questão nacional, no caso, em Paulo Freire, do que uma

2. Carta escrita do cárcere da ditadura de 1964, intitulada "Até quarta, Isabela". 
análise contemporânea, por certo premente, acerca do tema em nosso continente. Ocorre que, porém, na compreensão histórica pode-se alcançar a compreensão do presente e entender que as bases do nacionalismo de hoje passam, sem dúvida, por um passado de lutas e resistência, também devendo ser este o desiderato de todo pesquisador latino-americano.

\section{Paulo Freire e o nacional- desenvolvimentismo}

Tomaremos, não sem certo risco, uma opção por conceber a obra de Paulo Freire em dois tempos diferentes. Em um primeiro momento, destacaremos a fase em que esteve mais ligada ao pensamento originado no ISEB - Instituto Superior de Estudos Brasileiros, sendo seu amálgama último o nacionaldesenvolvimentismo. Em um segundo momento, porém, tal pressuposição teórica se esvaecerá na obra de Freire, ressaltandose a fase do exílio e seu contato com a obra marxista. Neste ponto é que poderemos melhor compreender a contribuição freireana para a questão nacional latino-americana. Um último momento ainda poderia ser assinalado, mas este não será objeto de nossas reflexões, seja por razão de limites espaçotemporais, seja pelo fato de destoar da apreensão que este texto pretende oferecer. Cabe, porém, uma periodização - como a que fizemos destacando as obras mais significativas de cada um dos momentos: um primeiro Paulo Freire, melhor compreendido em Educação como prática da liberdade; um segundo, caracterizado pela Pedagogia do Oprimido; e um último, consubstanciado em Pedagogia da Autonomia.

Paulo Freire inaugura sua produção teórica com a tese apresentada em concurso para professor de História e Filosofia da Educação da Escola de Belas Artes de Pernambuco. A tese, de 1959, se chamou Educação e atualidade brasileira, e seria, grosso modo, reescrita cinco anos depois, com algumas alterações, dandose a conhecer por Educação como prática da liberdade.

Segundo Paiva (1979, p. 9), este primeiro Freire cuja produção teórica traria a lume "o preâmbulo à pedagogia do oprimido" (ou seja, os livros de 1959 e 1964) estaria "vinculado ao nacionalismo brasileiro da época". Esta conclusão destina-se a, por parte da autora, aproximar criticamente Paulo Freire dos grandes nomes do anticolonialismo (como Franz Fanon e Albert Memmi), ainda que guardadas as devidas proporções. A mesma autora é quem dita o seguinte entendimento: "absorvido pelo trabalho prático desde a criação do seu método, restara a Freire pouco tempo para o trabalho teórico", vale dizer, "sua consciência teórica já não dava conta de toda a sua prática" (PAIVA, 1986, p. 141). Ainda, resgata o prefácio de Francisco Weffort à edição de Educação como prática da liberdade para quem "a teoria teve de esperar que o exílio do autor lhe permitisse um esforço de sistematização" (WEFFORT, 1996, p. 11).

Apesar de considerarmos corretas estas interpretações, elas não devem ser entendidas como uma possibilidade de se dicotomizar teoria e prática na obra de Paulo Freire, mas, sim, como um momento que expressa transição e ruptura com as fundamentações iniciais às quais ele recorria.

Desse modo, fica patente o comprometimento de Paulo Freire com a prática educativa, bem como que sua maturação pedagógica levaria o tempo necessário para ser compreendida mais sistematicamente dentro da luta pela desopressão, coerente, inclusive, com seu entendimento do homem, incompleto e imperfeito, antes de tudo.

De fato, Paulo Freire apresenta em suas obras iniciais um tom muito mais próximo do isebianismo do que se costuma 
lembrar hoje em dia (o que se acentua, por sua vez, mais no primeiro livro que no segundo). Mas, neste sentido, ficamos com o entendimento de Ana Inês Souza, quando diz:

[...] resgatar o pensamento de Paulo Freire nos idos de 1959 é um desafio ímpar e apaixonante para quem, quarenta anos depois do chamado 'nacional-desenvolvimentismo', está envolvida na discussão do Projeto Popular para o Brasil. (SOUZA, 2006, p. 33).

Como Freire ontem, todos os que, hoje, recusam uma educação neutra e uma pedagogia vertical e bancária, têm de se posicionar politicamente em prol do popular e, nesta toada, podemos mesmo concluir pela inextricabilidade entre os conceitos de nacional e popular. É certo que, assim, incorre-se no risco de reaproximar duas ideias que, em suas versões extremadas, devem ser superadas, quais sejam: o nacionalismo e o populismo. No entanto, este risco torna-se tanto menos provável quanto mais a posição política se define em contrariedade ao sistema dado de coisas, ou seja, à opressão do capital e à subjugação dos países periféricos.

Isto tudo nos faz remeter a Paulo Freire (1996), em sua abordagem sobre a "sociedade brasileira em transição". Trata-se, claramente, de um apelo ao nível nacional que busca se desvelar criticamente em favor da libertação. Da sociedade em transição passa-se à democratização cultural que se impõe como necessária e, desta, à necessidade de se ter como foco de reflexões o homem brasileiro:

[...] assim como não podemos perder a batalha do desenvolvimento, a exigir, rapidamente, a ampliação de nossos quadros técnicos de todos os níveis (a mão-de-obra qualificada do País é de 20\% apenas), não podemos perder a batalha de humanização do homem brasileiro. (FREIRE, 1996, p. 105).

A passagem é exemplar, no que toca à hibridação do pensar freireano. Ao tempo do ISEB, um nacional-desenvolvimentista renomado, como Celso Furtado, diria, referindo-se à inflação, que "a estabilidade é um objetivo fundamental, mas que deve subordinar-se a outro mais amplo que é o desenvolvimento" (FURTADO, [19--], p. 259). Sua solução, todavia, não olvidaria da questão nacional em favor da do desenvolvimento:

não é possível seguir uma política ordenada de desenvolvimento se não se dispõe de um efetivo comando sobre esse instrumento fundamental que é o sistema bancário. (FURTADO, [19--], p. 260).

Prognosticar o controle do sistema bancário, hoje, mais do que nunca, significa obter um controle sobre o mercado que se fetichiza em sua financeirização e transnacionalização, perdendo o vínculo com o nacional e com a responsabilidadediantedaseconomiasespecíficas.

Paulo Freire também se referia ao desenvolvimento, mas sua reflexão, quanto à temática da educação, incidia sobre $\mathrm{O}$ homem brasileiro, daí seu ad-mirar nacional:

[...] até o ISEB, a consciência dos intelectuais brasileiros ou da grande maioria daqueles que pensavam e escreviam dentro do Brasil tinha como ponto de referência tanto para o seu pensar como para a própria avaliação do seu pensar a realidade do Brasil como um objeto do pensar europeu e depois norte-americano. Pensar o Brasil, de modo geral, era pensar sobre o Brasil, de um ponto de vista não-brasileiro. Julgava-se o desenvolvimento cultural do Brasil segundo critérios e perspectivas nos quais o País era necessariamente um elemento estrangeiro. É evidente que este era fundamentalmente um modo de pensar alienado. (FREIRE, 1996, p. 106).

Fica claro, portanto, que apesar de as mais variadas influências que se exerceram sobre Freire, ele foi portador de uma síntese 
pedagógica, para além de uma mera construção pedagógica. Ou seja, não foi seu pensamento tomado por um ecletismo que não permitisse ter uma posição bem definida sobre seu quefazer, pois, como diria Roberto Gomes (1979, p. 33), "no ecletismo, retratamos nossas hesitação em assumir um ponto de vista que nos permitisse uma síntese original". É justamente o contrário que caracteriza Freire: uma síntese teórica nem um pouco neutra - porque para a liberdade -, ainda que tributária do existencialismo cristão, do culturalismo e do escolanovismo.

Podemos recuperar outro exemplo do primeiro Paulo Freire, agora em seu primeiro livro, a tese Educação e atualidade brasileira, ao fazer um comentário introdutório em que resgata o pensamento de Vieira Pinto e sua "ideologia do desenvolvimento":

[...] medite-se, ainda, no que representa para países subdesenvolvidos como o Brasil, mas em processo de desenvolvimento, a inserção do povo no esforço da recuperação econômica de suas comunidades. E não só econômica, mas política e social. O que representa a criação e a amplitude de uma consciência popular do desenvolvimento. O sentido da responsabilidade social do homem. O que não poderão fazer comunidades assim ideologizadas no esforço de sua recuperação. (FREIRE, 2003, p. 21, grifos do autor).

Eis aí, pois bem, uma síntese do pensamento freireano nos "preâmbulos da pedagogia do oprimido". Entre a análise da alienação e da conscientização, abertas estariam portas para a recepção crítica do cabedal marxista, bem como a prática deixaria de se realizar "localizadamente", como, dentre outras, na experiência de Angicos, mas se tornaria internacional e dialogada, à enésima potência, com várias culturas distintas.

\section{Paulo Freire e a Pedagogia do Oprimido}

Como já reiterado, o exílio seria momento de aprofundamento e de rigorosa sistematização para Paulo Freire. Destaquemos aqui alguns momentos de sua trajetória intelectual e prática para que possamos nela ver o desdobramento da questão nacional. Antes de tudo, é significativo resgatar a reflexão de Freire a respeito da dependência latino-americana como um fenômeno relacional, ou seja, como uma relação de poder em favor da tradição metropolitana contra a cultura colonial. Trata-se de uma cultura do silêncio, da apatia e da não participação democrática. Freire vai interpretar, então, a crescente das massas como o rompimento dessa cultura, dando azo a contradições que favorecem a emersão das consciências até aí assujeitadas:

[...] ainda mais, se um grupo de apodera do poder por um golpe de Estado - como no caso recente do Peru - e começa a tomar medidas de defesa econômica e cultural de tipo nacionalista, sua política cria uma nova contradição. O novo regime pode ir além de suas próprias intenções e ver-se obrigado a romper definitivamente com a "cultura do silêncio", tanto no exterior como no interior, ou - temendo o ascenso do povo - voltar atrás e tratar de impor novamente o silêncio às massas. (FREIRE, 1980, p. 65).

Enfim, está a se referir ao fato de que “o populismo terminará por criar sérias contradições" (FREIRE, 1980, p. 65). A título de introdução, esta interpretação do fenômeno da dependência dentro do binômio nacionalismopopulismo já demonstra a guinada de perspectiva do pensamento freireano, devido ao rumo que sua vida se obrigou a tomar.

Em suma, para Freire (1980, p. 71), "na América Latina, o golpe de Estado veio a ser a resposta das elites econômicas e militares às crises provocadas pela emergência popular". Isto significa dizer que a efervescência do "período populista" era muito mais que cultural, no sentido das artes, pois que também de transição política, sugerindo a própria revolução: "clima 
de pré-revolução, cuja contradição dialética é o golpe de Estado" (FREIRE, 1980, p. 71). Tendo em vista esta interpretação inicial, é possível avançarmos para outros momentos da reflexão nacional em Freire. Dussel (1997, p. 44) advertia para o fato de que

[...] um certo "nacionalismo" cultural lançounos ao encontro do nacional. É necessário dar um passo a frente e descobrir a América Latina para salvar nossa própria cultura nacional. É necessário, então, superar tal nacionalismo!

Tal admoestação já fora incorporada por Paulo Freire, quando, no Chile, atuou no processo de planejamento da reforma agrária. Ali, o nacional, anteriormente tão exaltado, transforma-se no continental que, como Dussel haveria de dizer, seria condição de salvaguarda das culturas nacionais. O próprio Freire daria argumentos para esse prisma de análise:

[...] de um ponto de vista mais crítico e de uma visão mais histórica, para a América Latina como para o Terceiro Mundo em geral, não somente a capacitação técnica, mas qualquer outra dimensão educativa popular, no processo de reforma agrária ou não, tem que estar associada a este esforço através do qual os homens simples se decifram a si mesmos como homens, como pessoas proibidas de ser. (FREIRE, 1985, p. 92).

No Chile, Freire também poderia ter elaborado sua "pedagogia do oprimido", verdadeiro monumento da Teoria da Libertação na América Latina. Para além de aprofundar e ressistematizar suas ideias, ele optou por fazer uma dura crítica à teoria da ação antidialógica (no âmbito da educação, a concepção bancária). Quiçá o mais interessante para a reflexão do nacional aí seja, justamente, as características de tal ação antidialógica, em especial, a "invasão cultural", conceituada da seguinte maneira:
[...] penetração que fazem os invasores no contexto cultural dos invadidos, impondo a estes sua visão do mundo, enquanto Ihes freiam a criatividade, ao inibirem sua expansão. (FREIRE, 2004, p. 149).

A despeito de não haver nenhuma referência explícita à questão nacional, esta se torna patente à medida que o centro das atenções se torna a ação cultural dialógica e a revolução cultural, como, respectivamente, anteriores e posteriores ao processo revolucionário. Ou seja, trata-se de um convite a que todos participem da "reconstrução da sociedade".

Como não poderia deixar de ser, esta reflexão não dá mais primazia à questão nacional, em sentido explícito, por ser tributária do marxismo. Todavia, as sempre presentes mençõesà "sociedade" acompanhadas dolegado maoísta acerca da revolução cultural implicam o reconhecimento deste pano de fundo. Para corroborar nossa argumentação, demonstremola via próprias palavras de Paulo Freire:

[...] não é possível o desenvolvimento de sociedades duais, reflexas, invadidas, dependentes da sociedade metropolitana, pois que são sociedades alienadas, cujo ponto de decisão política, econômica e cultural se encontra fora delas - na sociedade metropolitana. (FREIRE, 2004, p. 159).

Por derradeiro, insta-nos rápida visão da atuação de Freire na África como decorrência de sua prática pedagógica "subversiva", a qual não tinha guarida em seu país natal.

Ao abordar a problemática da Tanzânia, a seu pedido, Freire comentaria sobre a construção feita por seu presidente em termos de educação, sendo que uma das propostas

[...] tem que ver com o caráter político da educação, é a ênfase que o Presidente Nyerere dá à participação crítica de seu Povo, como sujeito no processo de desenvolvimento do País. Para Nyerere, não há desenvolvimento sem a presença curiosa e responsável das 
massas populares na reconstrução da sua sociedade. (FREIRE, 1984, p. 37).

Aí se percebe o respeito de Freire pela cultura tanzaniana, mas, ao mesmo tempo, sem abdicar de balizas muito bem sedimentadas quanto à sua opção política. A sociedade socialista que Freire também queria construir não poderia se furtar de unir o nacional ao universal, no sentido da luta pela libertação, pois fora disto,

[...] a minha pesquisa só tem sentido se a minha opção política é pela dominação e não pela libertação dos grupos e das classes sociais oprimidas. (FREIRE, 1984, p. 35).

Outra experiência salutar seria a de São Tomé e Príncipe, na ajuda dada por Freire ao governo independente recém-descolonizado. Ali, ele participou da redação dos Cadernos de Cultura Popular, os quais primariam por "uma compreensão crítica do momento de transição revolucionária em que se achava o país" (FREIRE, 1987, p. 46).

Os Cadernos trariam uma grande riqueza política para a educação, como se pode observar em algumas passagens:

[...] com o MLSTP [Movimento de Libertação de São Tomé e Príncipe] estamos a construir uma sociedade em que todos participam para o bem-estar de todos. Precisamos estar vigilantes contra aqueles que pretendem começar de novo o sistema de exploração das maiorias por uma minoria dominante. (FREIRE, 1987, p. 59).

Sob o título "reconstrução nacional", segue um excerto citado por Freire:

[...] vimos, no texto anterior, que produzir mais nas roças, nas fábricas e trabalhar mais nos serviços públicos é lutar pela reconstrução nacional. Vimos também que a reconstrução nacional, para nós, significa a criação de uma sociedade nova, sem explorados nem exploradores. Uma sociedade de trabalhadores e de trabalhadoras. Por isso, a reconstrução nacional exige de nós: unidade, disciplina, trabalho e vigilância. (FREIRE, 1987, p. 71).

Estas quatro últimas palavras parecem resumir a temática do nacional em Paulo Freire. Apesar de incluídas em um específico contexto, o pós-colonialismo africano, representam um pouco da síntese freireana a respeito do assunto.

Freire teve muitas outras experiências, mas as apontadas aqui tendem a nos fazer crer em uma suficiente análise introdutória ao tema. A partir delas, bem como do que assinalamos anteriormente dentro da concepção freireana, podemos distinguir alguns traços contínuos de sua obra, vale dizer, o privilégio à prática, a consciência crítica, o respeito cultural e a aproximação final entre os conceitos de nacional e popular, em especial, dentro de processos de reestruturação das sociedades nas quais trabalhou.

Esta abordagem histórica dada ao pensamento de Freire quanto à reflexão do nacional, permite-nos entrever que a própria história tem suas saliências, sulcos que ficam recônditos e que precisam ser entrevistos novamente para que entendamos que sua narrativa é feita pelos vencedores. Mas os vencidos, explorados, dominados, não deixam de resistir; quando a história parece ter chegado a seu fim ela nos surpreende e, aí sim, começa verdadeiramente. Como diria Freire, "o passado não se muda. Compreende-se, recusa-se, aceitase, mas não se muda". Já "o futuro é dos Povos e não dos Impérios" (FREIRE, 2000, p. 73-76).

Tivemos por objetivo refletir sobre a produção teórica de Paulo Freire, tomando a questão nacional, a fim de compreendermos as consequências de sua interpretação para suas opções epistemológicas. Ao ressaltarmos dois momentos de sua produção que ensejam cargas semânticas e políticas distintas à problemática nacional - o desenvolvimentismo e a crítica à dependência conectada à reconstrução de uma 
sociedade de novo tipo - cremos ter evidenciado sua contribuição, a partir das transformações de seu pensamento mesmo, para a superação das apostas políticas de "mudança marginal", como diria Fals Borda (1979), em prol de transformações estruturais, revolucionárias.

\section{Referências}

BOAL, A. Teatro do oprimido e outras poéticas políticas. 6 ed. Rio de Janeiro: Civilização Brasileira, 1991.

DUSSEL, E. D. Cultura, cultura latino-americana e cultura nacional. In: DUSSEL, E. D. Oito ensaios sobre cultura latino-americana e libertação. Tradução de Sandra Trabucco Valenzuela. São Paulo: Paulinas, 1997.

DUSSEL, E. D. Filosofia da libertação. 2 ed. Tradução de Luiz João Gaio. São Paulo: Loyola, [198-].

FALS BORDA, O. As revoluções inacabadas na América Latina (1809-1968). Tradução de J. Teixeira Coelho Netto. São Paulo: Global, 1979.

FREIRE, P. A importância do ato de ler: em três artigos que se completam. 18. ed. São Paulo: Cortez, 1987.

FREIRE, P. Conscientização: teoria e prática da libertação: uma introdução ao pensamento de Paulo Freire. 3. ed. São Paulo: Moraes, 1980.

FREIRE, P. Criando métodos de pesquisa alternativa: aprendendo a fazê-la melhor através da ação. In: BRANDÃO, C. R. (Org.). Pesquisa participante. 4. ed. São Paulo: Brasiliense, 1984.

FREIRE, P. Educação como prática da liberdade. 22. ed. Rio de Janeiro: Paz e Terra, 1996.

FREIRE, P. Educação e atualidade brasileira. 3. ed. São Paulo: Cortez; Instituto Paulo Freire, 2003.

FREIRE, P. Extensão ou comunicação? 8. ed. Tradução de Rosisca Darcy de Oliveira. Rio de Janeiro: Paz e Terra, 1985.

FREIRE, P. Pedagogia da indignação: cartas pedagógicas e outros escritos. São Paulo: UNESP, 2000.

FREIRE, P. Pedagogia do oprimido. 39. ed. Rio de Janeiro: Paz e Terra, 2004.

FURTADO, C. A política monetária. In: FURTADO, C. et al. Inflação e desenvolvimento: textos básicos sobre as economias subdesenvolvidas. Petrópolis: Vozes, [19--].

GOMES, R. Crítica da razão tupiniquim. 3. ed. Porto Alegre: Movimento/ URGS, 1979.

GUTIÉRREZ, G. Teología de la liberación: perspectivas. 10. ed. Salamanca: Sígueme, 1984.

MOFFATT, A. Psicoterapia do oprimido: ideologia e técnica da psiquiatria popular. Tradução de Paulo Esmanhoto. 4. ed. São Paulo: Cortez, 1983.

PAIVA, V. P. Do "problema nacional" às classes sociais. Educação e sociedade, São Paulo: Cortez e Moraes, Ano I, n. 3, p. 5-14, maio 1979. 
PAIVA, V. P. Paulo Freire e o nacionalismo-desenvolvimentista. 2. ed. Rio de Janeiro, 1986.

SOUZA, A. I. Educação e atualidade brasileira: a emersão do povo na história. In: SOUZA, A. I. (Org.). Paulo Freire: vida e obra. 4. ed. São Paulo: Expressão Popular, 2006.

WEFFORT, F. C. Educação e política: reflexões sociológicas sobre uma pedagogia da liberdade. In: FREIRE, P. Educação como prática da liberdade. 22. ed. Rio de Janeiro: Paz e Terra, 1996.

Submetido em 9 de janeiro de 2013.

Aprovado em 28 de maio de 2013. 